\title{
Study of Outer Membrane Vesicles Isolated from B. abortus S19 by Bulk Production and Characterization
}

\author{
Losa Rose $^{1 *}$, Tejinder Singh Rai ${ }^{1}$, A. K. Arora ${ }^{1}$, Dipak Deka ${ }^{2}$ and L. Geeta Devi ${ }^{3}$ \\ ${ }^{1}$ Department of Veterinary Microbiology, ${ }^{2}$ College of Animal Biotechnology, \\ ${ }^{3}$ Department of Veterinary Pathology, Guru Angad Dev Veterinary and Animal Science \\ University, Ludhiana, Punjab, 141004, India \\ *Corresponding author
}

\section{A B S T R A C T}

\begin{tabular}{|l|}
\hline Ke y w o r d s \\
$\begin{array}{l}\text { Outer membrane } \\
\text { vesicles, Brucella } \\
\text { abortus, Vaccine, } \\
\text { SDS-PAGE, } \\
\text { Western Blotting. }\end{array}$ \\
\hline Article Info \\
\hline $\begin{array}{l}\text { Accepted: } \\
\text { 05 April } 2020 \\
\text { Available Online: } \\
\text { 10 May } 2020\end{array}$ \\
\hline
\end{tabular}

Outer membrane vesicles (OMV) are closed spheroid vesicles with size ranging between 20-500 nm produced by both Gram negative and Gram positive bacteria. OMV are formed by the blebbing and pinching off segments of bacterial outer membrane. They are composed of lipopolysaccharide (LPS), glycerophospholipids, outer membrane proteins (OMPs), and periplasmic components. They are found in a variety of environments including liquid culture, solid culture and biofilms as well as during periods of bacterial stress. Being small size and having immunogenic properties and non-replicative behavior they stand as a good choice for vaccination. Keeping in view of the above facts the present study has been carried out to explore the immunogenic properties of OMV by its isolation and characterization. Isolation of OMV from Brucella abortus S19 was carried out by growing in solid as well as liquid media and subsequently the growth was subjected to filtration and centrifugation steps. The OMV were characterized by electron microscopy. They were further analyzed by SDS-PAGE and Western Blotting. On electrophorectic profile they revealed protein bands of $86 \mathrm{kDa}, 70 \mathrm{Kda}, 65 \mathrm{kDa} 40 \mathrm{kDa}$ and immunore active band of $86,70,65 \mathrm{kDa}$ on western blotting.

\section{Introduction}

One of the most important bacterial diseases worldwide brucellosis has been classified by World Health Organization as world leading neglected zoonotic disease (OIE, 2010). It severely hinders livestock productivity and human health worldwide. Brucella abortus is the main causative organism in bovine. Bovine brucellosis has been reported in virtually all countries where cattle are farmed. The disease is endemic in India, a country that house the world's largest cattle and buffalo population and produce the most milk in the world.

Live vaccines like $B$. abortus strain 19 and $B$. abortus RB51 are the most commonly used vaccines for the control of brucellosis in various parts of the world. But they suffer 
from some inherent disadvantages of residual abortifacient activity in pregnant animals besides biosafety issues and also cannot be used in the males (Rose et al., 2018).

Bacterial pathogens have evolved various mechanisms to transport virulence factors to the eukaryotic host cells. This virulence factors aids in the colonization, immuneevasion, nutrient acquisition and other cellcell communication thus plays a major role in establishing successful host pathogen relationship.

The release of outer membrane vesicles (OMV) is one such important phenomenon that can disseminate bacterial products and interact with the environment. OMV also known as blebs enable bacteria to secrete insoluble molecules as well as soluble material attached to it and allow it to reach the target site in a concentrated, protected and targeted form.

The vesicles are produced spontaneously and during the normal growth of the bacteria (Beveridge, 1999) which can be found in different environments like soil, biofilms, and enriched culture medium and during the infective process of pathogens.

They play important biological functions on the environment and on other cells by playing an active part in pathogenesis, quorum sensing, horizontal gene transfer (Yaron, 2000). Like other Gram negative bacteria, Brucella also releases OMVs to the external environment (Boigegrain et al., 2004).

Purification of OMV relies on their small size and buoyant density, allowing them to be separated from the bacterial cells by centrifugation or ultrafiltration (Kuehn and Kesty, 2005). Earliest work done can be date back in 1989 by Gamazo and his co-workers who worked on outer membrane blebs of $B$. melitensis and studied the protein profile. Various authors tried growing the vesicles in solid as well as liquid media. However, they reported the yield in solid media yielded more vesicles as compared to liquid media.

\section{Materials and Methods}

\section{Bacterial strains and growth conditions}

The Brucella abortus S19 used in this study was procured from the Department of Veterinary Microbiology, GADVASU, Ludhiana. The culture was grown in Brucella selective medium (BSM) prepared in Petriplates with Brucella growth supplements and incubated at $37^{\circ} \mathrm{C}$ for $48 \mathrm{~h}$.

\section{Preparation of OMV}

OMV were isolated from B. abortus S19 by using a procedure discussed previously (Gamazo et al., 1989). The Brucella abortus S19 cultures were grown on a Roux flasks and Petri-plates containing BSM and incubated for $2-3$ days at $37^{\circ} \mathrm{C}$. When sufficient and enough growth had obtained the culture was harvested with PBS pH 7.4.

The bacterial suspension was centrifuged at $10,000 \times \mathrm{g}$ for $30 \mathrm{~min}$. The supernatant was filtered with $0.22 \mu$ syringe filter. The filtered supernatant was centrifuged at $100,000 \times \mathrm{g}$ for $2 \mathrm{~h}$ at $4^{\circ} \mathrm{C}$ using Optima XPN-100 Ultracentrifuge. OMV pellet was resuspended in $100 \mu$ of sterile PBS. OMVs samples were divided into aliquots and stored at a temperature of $-80^{\circ} \mathrm{C}$ until use.

\section{Electron microscope -negative stains}

The OMV sample was fixed in $0.5 \%$ glutaraldehyde and kept for incubation for $1 \mathrm{~h}$ at $4^{\circ} \mathrm{C}$. $10 \mu \mathrm{l}$ of the OMV sample were allowed to adsorb onto copper coated grid for 5-10 min followed by staining with 
phosphotoungstic acid (2\%). The grid was dried and was examined in electron microscope (Hitachi H-7650).

\section{Protein assay}

Protein content was determined by Bicinchoninic acid (BCA) method described by $\mathrm{He}$ (2011) using bovine serum albumin as standard.

\section{Sodium dodecylsulphate -polyacrylamide gel electrophoresis (SDS-PAGE)}

SDS-PAGE (Biorad) analysis was carried out as per Laemmli (1970) with slight modification (Laemmli, 1970). The gel casting platforms were assembled and sealed. The stacking (5\%) and separating gels (12\%) were prepared. A volume of $30 \mu 1$ of OMVs containing $90 \mu \mathrm{g}$ of the protein was mixed with an equal volume of $2 \mathrm{X}$ sample loading buffer. The gel was stained with Coomassie brilliant blue (CBB).

\section{Western blotting}

The OMV obtained from B. abortus cells were subjected to immunoblot analysis. Proteins were transferred from polyacrylamide gels to nitrocellulose membrane and incubated with mouse immune sera directed against OMV. The immunochemical detection was performed using goat anti-mouse IgG- HRP.

\section{Results and Discussion}

OMV have been explored as a vaccine candidate due to its immunomodulatory role and unique delivery systems. Several licensed vaccines are based on OMV (Jackson et al., 2009). OMV encase various immunogens and appear to be safe as vaccines (Granoff, 2010). Vesicle components like LPS and OM porins acts as pathogen associated molecular patterns
(PAMPs) that are presented to the first line of immune system. They are recognized by pattern recognition receptors (PRRs) like tolllike receptors (TLRs) which produce inflammatory response in association with the complement system (Amano et al., 2010).

The B. abortus culture inoculated in solid media Brucella Selective Medium (BSM) prepared in Roux flasks and Petri-plates were used to obtained OMV. The growth was harvested in PBS and bacterial harvest was subjected to filtration steps. The bacteria free filtrate (BFF) were subjected to ultracentrifugation $(1,00,000 \times \mathrm{g}$ for $2 \mathrm{~h}$ at $4^{\circ} \mathrm{C}$ ) which is one the significant step in the procurement of vesicles. The vesicles were seen as pellet at the bottom of the tube (Fig 1). The pellets were of transparent gel like consistency. After the supernatant has been discarded carefully the pellet were washed with PBS (pH 7.4) in sterile eppendorf and stored at $-80^{\circ} \mathrm{C}$ till its further use. Protease inhibitor cocktail was used to prevent protein degradation. Liquid medium was tried to procure the vesicles but the yield was comparatively less as compared to that from solid medium.

Previous studies were done on $B$. ovis and $B$. melitensis where the outer membrane blebs were extracted by growing on agar plates which were suspended in sterile phosphatebuffered saline. They demonstrated that $B$. ovis also produces blebs on solid media and in liquid media. However, the yield on solid media produced better results with larger size (Gamazo and Moriyon, 1987).

Negatively stained OMV sample showed multiple spherical vesicles with electron dense centre. The size of the vesicles ranged from 150-250 nm (Fig 2). The results were in conformity with the general size of OMVs as reported in Gram negative bacteria (Beveridge, 1999). Further the vesicles were 
found to form clumps and aggregates when observed under the microscopy. The protein profiles of OMVs were checked by sodium dodecyl sulfate polyacrylamide gel electrophoresis (SDS-PAGE) in 12\% gel. Denaturing gels stained with Coomassie blue allowed for visualization of the protein profile present in the OMV. Protein sizes of $40 \mathrm{kDa}$, $65 \mathrm{kDa}, 70 \mathrm{kDa}$ and $86 \mathrm{kDa}$ were observed (Fig 3). SDS-PAGE analysis of the free membranous material (FMM) and SarkosylZwittergent cell envelope (CE) revealed that both materials contained two major proteins $(30 \mathrm{kDa}$ and $25 \mathrm{kDa})$ and several minor protein bands (i.e. 18, 22, and $84 \mathrm{kDa}$ ) with similar apparent molecular weights (Gamazo and Moriyon, 1987).

Previous authors had reported the presence of 88, 66, 26, 23, 18 and $10 \mathrm{kDa}$ sized bands from OMVs of $B$. melitensis (Avila-Calderón et al., 2012). Two major bands (25kDa and 30 $\mathrm{kDa})$ and several minor bands $(18,22$, and 84 $\mathrm{kDa})$ in the OMVs of both smooth $B$. melitensis $16 \mathrm{M}$ and a rough strain $B$. melitensis B115 has also been reported (Gamazo et al., 1989). Differences in electrophoretic profile of OMV exists which may be due to the different strains (AvilaCalderón et al., 2012). There is also difference in SDS-PAGE profile between $B$. abortus RB51 and B. abortus RB51/SOD (Cassidy, 2010).

Immuno blotting was performed to ensure that Brucella abortus strain 19 OMV contain immune reactive proteins. The immune blotting was performed using goat anti-mouse HRP conjugate as secondary antibody. The hyperimmune serum raised against $B$. abortus S19 was used as a source of primary antibody in the study. Serum from mice on day $21^{\text {st }}$ post-immunization was used to study the immunore activity which was immunized with OMV S19.

Minor bands between 65, 70, 86 kDa (Fig 4) were observed in our study which may be of OMPs. Immunogenic proteins of OMVs of size $18 \mathrm{kDa}$ and $40-45 \mathrm{kDa}$ of $B$. abortus strain RB51 were also reported (Cassidy, 2010). Differences in the protein may be due to the different strains of Brucella used by other workers.

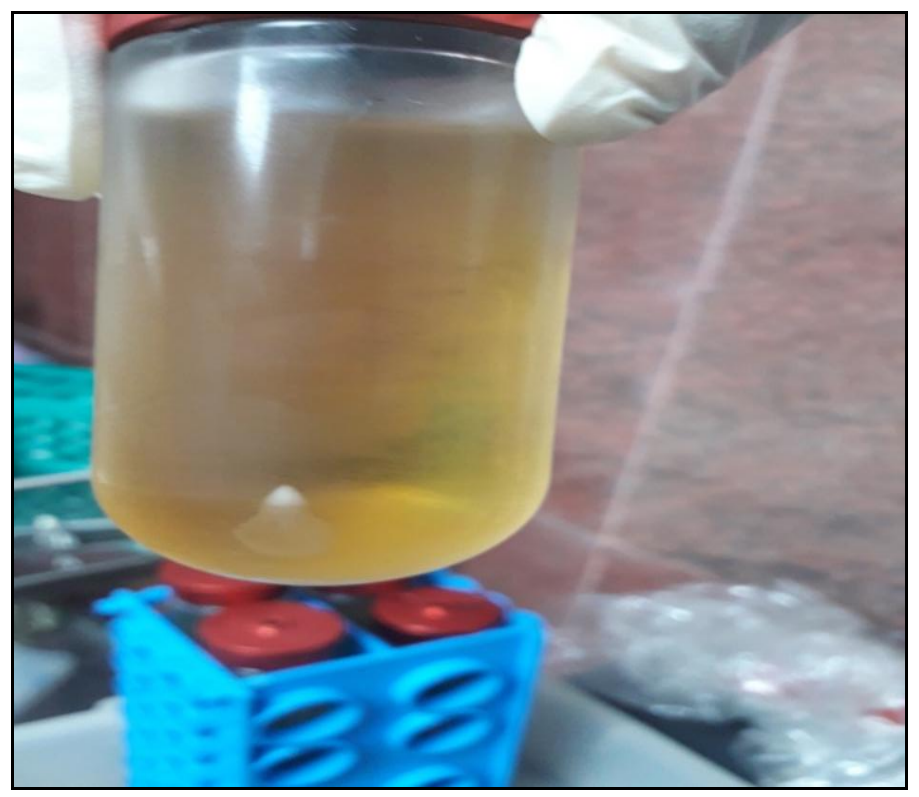

Fig.1 OMV seen as pellet after ultracentrifugation 


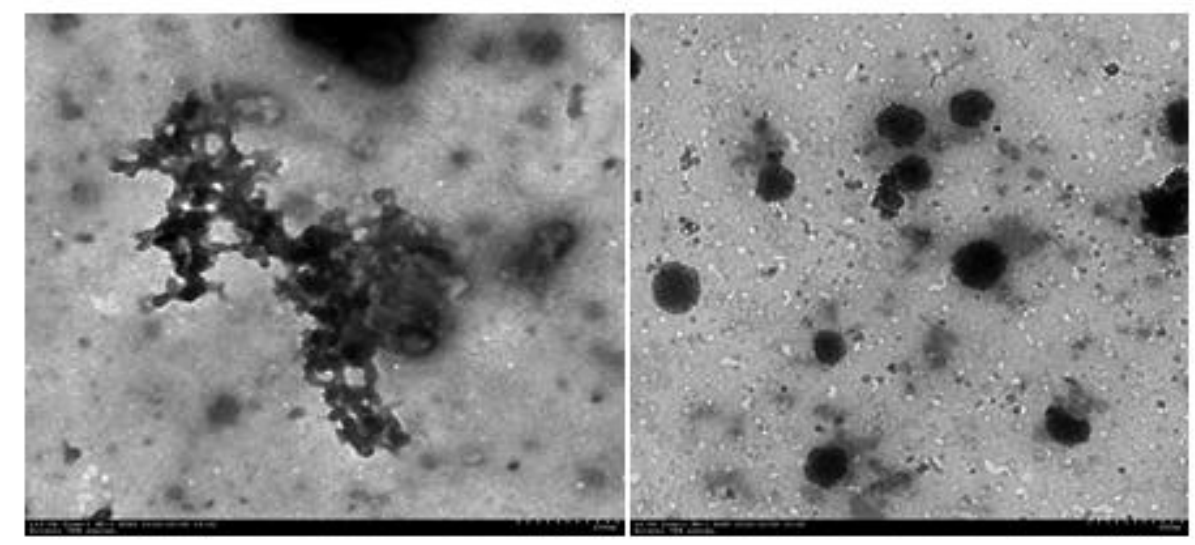

Fig.2 Transmission electron microscopy of OMV of B. abortusS19

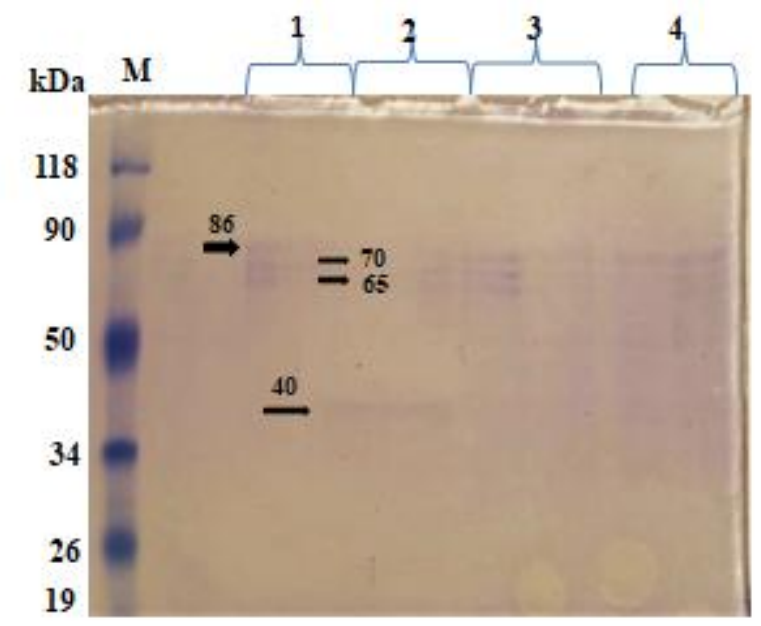

Fig.3 SDS-PAGE analysis of OMV of B. abortusS19

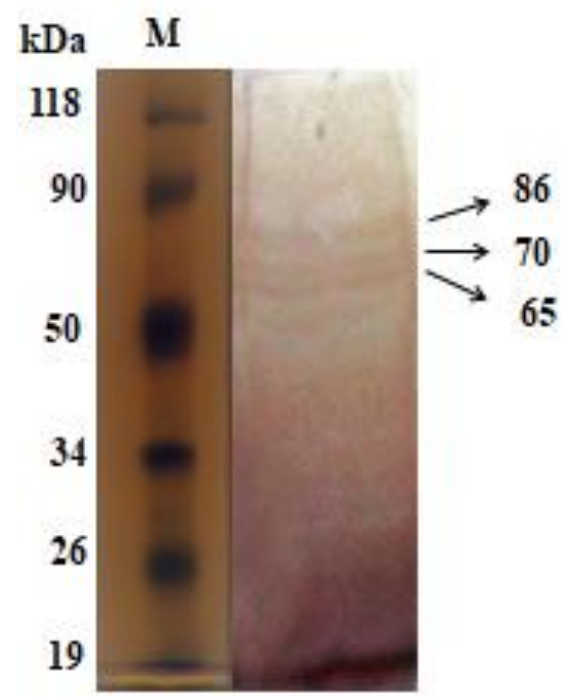

Fig.4 Western blot analysis of OMV of B. abortus S19 
The development of safe and effective vaccines against both animal and human disease will constitute an important step in curbing brucellosis. Like other Gram negative bacteria, Brucella also releases OMVs to the external environment (Boigegrain et al., 2010). The use of Brucella OMVs as a potential vaccine candidate has also been explored and previous studies has shown to purified OMVs from both $B$. melitensis smooth strains $16 \mathrm{M}$ and rough VTRM1 strain by differential centrifugation were used to immunize mice and was found to provide partial protection against direct challenge of B. melitensis in mice model (Avila-Calderón et al., 2012). This present study has demonstrated that OMV can be isolated and characterized by various methods as described above. Further studies are required to study the potential of OMV to check for the immune response studies and determined the efficacy as a vaccine candidate.

\section{Acknowledgement}

We are thankful to the Director Research, Guru Angad Dev Veterinary and Animal Sciences University, Ludhiana for providing the funds and facilities necessary to carry out the research work.

\section{References}

Amano, A., Takeuchi, H., Furuta, N. 2010. Outer membrane vesicles function as offensive weapons in host-parasite interactions. Microb Infect.12:791798.

Avila-Calderón, E.D., Lopez-Merino, A., Jain, N., Peralta, H., López-Villegas, E.O., Sriranganathan, N., Boyle, S.M., Witonsky, S., Contreras-Rodríguez, A. 2012. Characterization of outer membrane vesicles from Brucella melitensis and protection induced in mice. Clin Exp Immunol. 352493.
Beveridge, T.J. 1999. Structures of Gramnegative cell walls and their derived membrane vesicles. J. Bacteriol. 181: 4725-4733.

Boigegrain, R.A., Salhi, I., Alvarez-Martinez, M.T., Machold, J., Fedon, Y., Arpagaus, M., Weise, C., Rittig, M., Rouot, B. 2004. Release of periplasmic proteins of Brucella suis upon acidic shock involves the outer membrane protein Omp25. Infect Immun. 72:5693-5703.

Cassidy, C.C. 2010. Brucella abortus Strain RB51 outer membrane vesicles as a vaccine against brucellosis in a murine model. Thesis submitted to the faculty of the Virginia Polytechnic Institute and State University

Gamazo, C and Moriyon, I. 1987. Release of outer membrane fragments by exponentially growing Brucella melitensis cells. Infect Immun. 55: 609-615.

Gamazo, C., Winter, A.J., Moriyon, I., RiezuBoj, J.I, Blasco, J.M., Diaz, R. 1989 .Comparative analyses of proteins extracted by hot saline or released spontaneously into outer membrane blebs from field strains of Brucella ovis and Brucella melitensis. Infect Immun. 57: 1419-1426.

Granoff, D.M. 2010. Review of meningococcal group B vaccines. Clin Infect Dis. 2: 54-65.

He, F. 2011. BCA (Bicinchoninic Acid) Protein Assay. Bio-101: e44. doi: 10.21769/BioProtoc.44

Jackson, C., Lennon, D.R., Sotutu, V.T., Yan, J., Stewart, J.M., Reid, S., Crengle, S., Oster, P., Ypma, E., Aaberge, I., Mulholland, K., Martin, D.R. 2009. Phase II meningococcal $\mathrm{B}$ vesicle vaccine trial in New Zealand infants. Arch. Dis. Child. 94:745-751.

Kuehn, M.J. and Kesty, N.C. 2005. Bacterial outer membrane vesicles and the host- 
pathogen interaction. Genes Dev. 19:2645-2655.

Laemmli, U.K. 1970. Cleavage of structural proteins during the assembly of the head of bacteriophage T. Nature. 277:680-685.

Rose, L., Kumar, B., Jain, A., Singh, M.K., Abhishek, Milton, A.A.P. 2018. Acellular outer membrane vesicles of Brucella abortus strain 19 elicits both humoral and cell mediated immune response in mice. Indian J. Anim.
Res.52: 1317-1323.

World Organisation for Animal Health (OIE). 2010. - Bovine brucellosis, Chapter 2.4.3. In Manual of Diagnostic Tests and Vaccines for Terrestrial Animals, OIE, Paris.

Yaron, S., Kolling, G.L., Simon, L., Matthews, K.R. 2000. Vesiclemediated transfer of virulence genes from Escherichia coli $\mathrm{O} 157: \mathrm{H} 7$ to other enteric bacteria. Appl. Environ. Microbiol. 66:4414-4420.

\section{How to cite this article:}

Losa Rose, Tejinder Singh Rai, A. K. Arora, Dipak Deka, L. Geeta Devi. 2020. Study of Outer Membrane Vesicles Isolated from B. abortus S19 by Bulk Production and Characterization. Int.J.Curr.Microbiol.App.Sci. 9(05): 112-118. doi: https://doi.org/10.20546/ijcmas.2020.905.011 